DOI: https://doi.org/10.47405/mjssh.v5i3.371

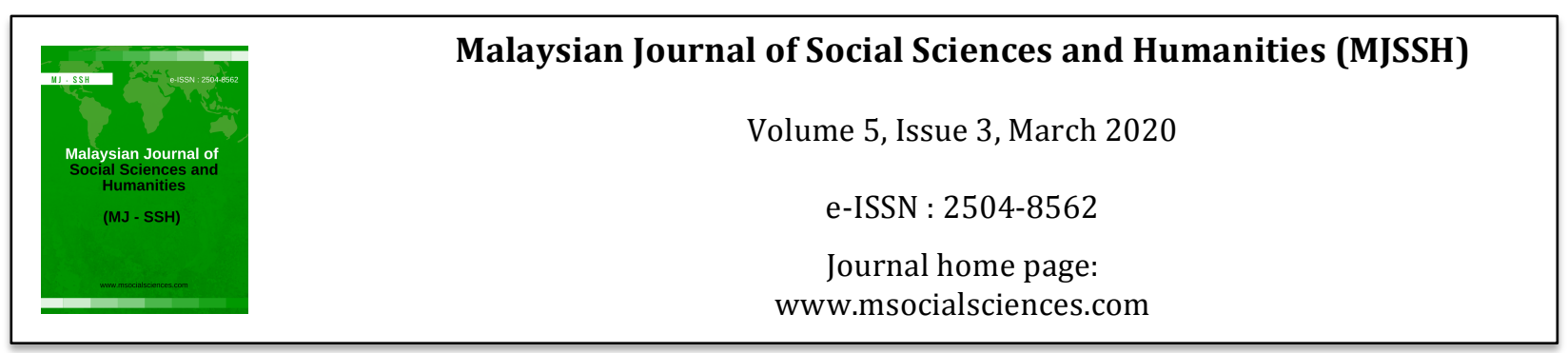

\title{
Zero-Waste Campaign: Assessment on University Student's Behaviour, Awareness, and Impact on Plastic Products
}

\author{
Izzah Abd Hamid1, Wan Asrina Wan Yahaya1 \\ 1Department of Crop Science, Faculty of Agriculture and Food Sciences, Universiti Putra Malaysia Kampus Bintulu \\ (UPMKB), Sarawak
}

Correspondence: Wan Asrina Wan Yahaya (asrina@upm.edu.my)

\begin{abstract}
Plastic products are cheap and practically easy to use in human daily life. However, the product is wellknown for being difficult to decompose and have become a main source of environmental pollution. Hence, it is important to continuously educate the young generation on the importance of environmental pollution and conservation. Therefore, our objective is to assess the behaviours and awareness of students who are using plastic products and the impact of the zero-waste campus campaign in Universiti Putra Malaysia Bintulu Sarawak Campus (UPMKB). About 249 respondents were interviewed face to face using designed survey forms, after a year the campaign had been launched. The results indicated that the respondents' behaviour was still dependent on plastic products. However, their awareness was considered alert enough with $46.79 \%$ being aware that the products were difficult to decompose. The imposed levy charge of MYR0.50 (USD0.12) in UPMKB provided a significant impact on reducing plastic usage where $83.94 \%$ supported the campaign by bringing their own food containers. The outcomes from this campaign may continuously raise awareness behaviour among future generations to reduce plastics usage and to conserve nature.
\end{abstract}

Keywords: plastic products, zero-waste campus, incentive, behaviour, awareness

\section{Introduction}

The use of plastic products (PP) makes a person's life easier due to them being lightweight, convenience, abundantly available, and even printed with various patterns for consumer usage. However, PP is rarely reused as it easily is torn, dirty, and sometimes it loses its ability to be used after several uses, which later become a pollution. The common problem reported by the researcher was the destructive and unpleasantness to the eyes when PP is being thrown into the surrounding environment (Moharam and Maqtari, 2014), affecting the marine ecosystem (Heidbreder et al., 2019) and could potentially emit poisonous gases (Afroz et al., 2017). Moreover, when this PP ends up in landfill, it will need almost 1,000 years to degrade (Kale et al., 2015).

Many countries have lunched campaigns on PP limiting its usage through media and imposed levy tax. In Malaysia, Pulau Pinang is the first state introducing "No Plastic Bag Day" in 2009, and was later followed by Selangor (Asmuni et al., 2015; Kuppusamy and Gharleghi, 2015). While European countries such as Germany and Denmark have started as early as in 1991 and 1994, respectively (Xanthos and Walker, 2017). To date in Malaysia, consumers have to pay MYR0.20 (USD0.05) to MYR1.00 (USD0.24) per piece to the shop if they need one during the purchase of goods. The levy 
charge was as well applied in Germany, Ireland, South Africa, and other countries (Xanthos and Walker, 2017). The charged was substantially successful to reduce PP usage and to awaken the public concern. Nevertheless, some developing countries e.g. Botswana, did confront obstacles because of poor regulatory framework and had strived till now to have an effective levies collection (Madigele and Mogomotsi, 2017).

In order to get satisfactory results in reducing the use of PP, an increase in the consumers' awareness is important through education. This is supported by Srinivasan et al. (2019) and Hammami et al. (2017) who have proven that in order for a country to have excellent environmental awareness education is necessary, to build citizens with strong pro-environmental characters and public health concern. At some extent, implementation of an effective legislation on PP prohibition is necessary to ensure that the community and related industries understand that the government cares about the following problems (Joseph et al., 2016). Therefore, our study assessed the behaviours and awareness of the students using PP and the impact of a zero-waste campus campaign in Universiti Putra Malaysia Bintulu Sarawak Campus.

\section{Methods}

This study was undertaken in March up to May 2019, in Universiti Putra Malaysia Bintulu Sarawak Campus (UPMKB), applying indirect face to face interviews together with designed survey forms. Out of 300, only 249 survey forms were returned with complete answers. All the respondents were chosen randomly, and their involvement was voluntary. The questions were divided into four sections according to the research objective. The first section, namely section A was on respondents' demographic such as their programme and semester enrolment, year of birth, gender and marital status. Section B mainly focused on their behaviour on using PP with questions on the usage of PP per week, type of PP, their preference on reuse of the bags, reason on not reusing the bags and reason on the reuse of the bags. In section $\mathrm{C}$, the questions are more on awareness on the recent campaign launched by our country, their supported behaviour on the campaign, the implication of using PP on the environment and the estimated time of PP decomposition. Lastly, section D was on the impact of the zero-waste campus campaign that had been launched in UPMKB through their participation in supporting this campaign, the impact after a year of this campaign, implication on a levy on PP and their opinions on the increasing impact of the campaign in the campus.

Prior to this study, a pilot test had been conducted among 10 students in order to verify the consistency and understanding of the questions. All collected data were then analysed in the Statistical Package for Social Sciences version 23.0 using frequency of the data. Later, this was presented in a circular graph.

\section{Result and Discussion}

The demographic of the respondents was summarised in Table 1 where $53.01 \%$ of the respondents were female students. About $83.94 \%$ of the respondents were studying diploma in various fields such as agriculture, food estate management, agribusiness, agricultural engineering, fisheries, forestry and animal health and husbandry. While the rest of the respondents $(16.06 \%)$ had taken a bachelor's in Science Bioindustry, Agriculture (aquaculture) and Forestry Science (forest plantation). 
DOI: https://doi.org/10.47405/mjssh.v5i3.371

Table 1: Respondents' demographic profile

\begin{tabular}{lc}
\hline \multicolumn{1}{c}{ Categories } & Percentile (\%) \\
\hline Gender & 46.99 \\
Male & 53.01 \\
Female & \\
Age & \\
$19-21$ years & 65.86 \\
$22-24$ years & 16.47 \\
$25-29$ years & 17.67 \\
& \\
Education level & \\
Bachelor & 16.06 \\
Diploma & 83.94 \\
& \\
Years of study & \\
First & 33.73 \\
Second & 28.11 \\
Third & 24.10 \\
Fourth & 14.06 \\
\hline
\end{tabular}

\section{Behaviours on using different types of plastic products}

Assessment on the behaviours of the students has indicated that they have basically used PP in their daily life, nearly $77.51 \%$ of the respondents use $<5$ pieces of plastics on a weekly basis. This include food container (37.31\%), garbage bags $(22.39 \%)$, rolled clear plastics $(20.90 \%)$ and singlet $(19.40 \%)$. Half of the respondents $(50.20 \%)$ di decide to reuse the PP such as singlet and garbage bags to store garbage $(56.35 \%)$, goods and materials storing $(23.81 \%)$, food storing $(14.29 \%)$ and a hobby $(5.65 \%)$.

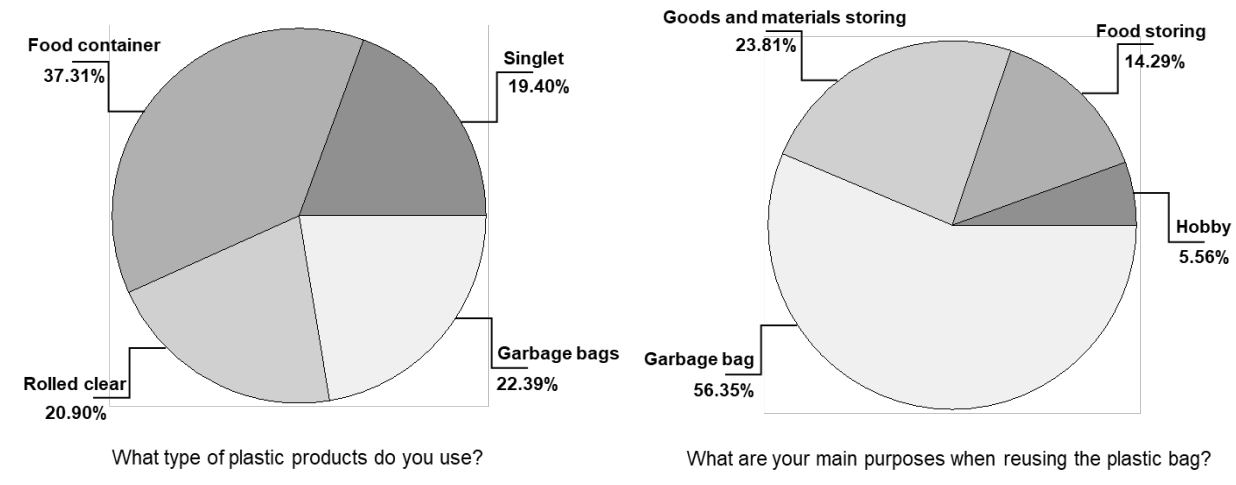

Figure 1: Respondents' behaviour on using plastic in their daily life

Use of PP in daily life cannot be easily diminished due to it being durable, lightweight, and others (Joseph et al., 2016; Moharam and Maqtari, 2014). It is notably common for the respondent to get a free plastic bag after purchase compared to bringing a recycle bag along to where they go. The most common PP use among university students is a food container to store food for a short period. This product is nearly impossible to be reused due to hygiene and it being improper to clean and to be used again. However, rolled clear, singlet, and garbage bags are easily used depending on the elasticity and appearance of the plastics by the respondents which comparable with Nurul Zarirah et al. (2016) and Zen et al. (2013). 


\section{Awareness of the implication of using plastic products}

The awareness analysis has indicated that $75.10 \%$ of the respondents were aware of the negative effect of PP on the environment with $91.97 \%$ of the respondents' who did support the campaign on reducing plastic usage in daily life. The analysis also indicated that $46.79 \%$ of the respondents firmly showed their awareness on the impact of using plastic which was hard to decompose upon disposal. It was also noted, that $29.49 \%$ of the respondents understood that PP had an effect on the ocean's organisms $19.87 \%$ contained dangerous synthetic chemical and $3.85 \%$ produced an unpleasant odour. The students were also asked on how long a PP will be fully decomposed. Nearly half of the respondents $(50.62 \%)$ gave the correct answer (i.e. 100 years), and $32.10 \%$ respondent replied not sure. Whilst, the remaining respondents indicated a mixed feedback on the questions (Figure 2).
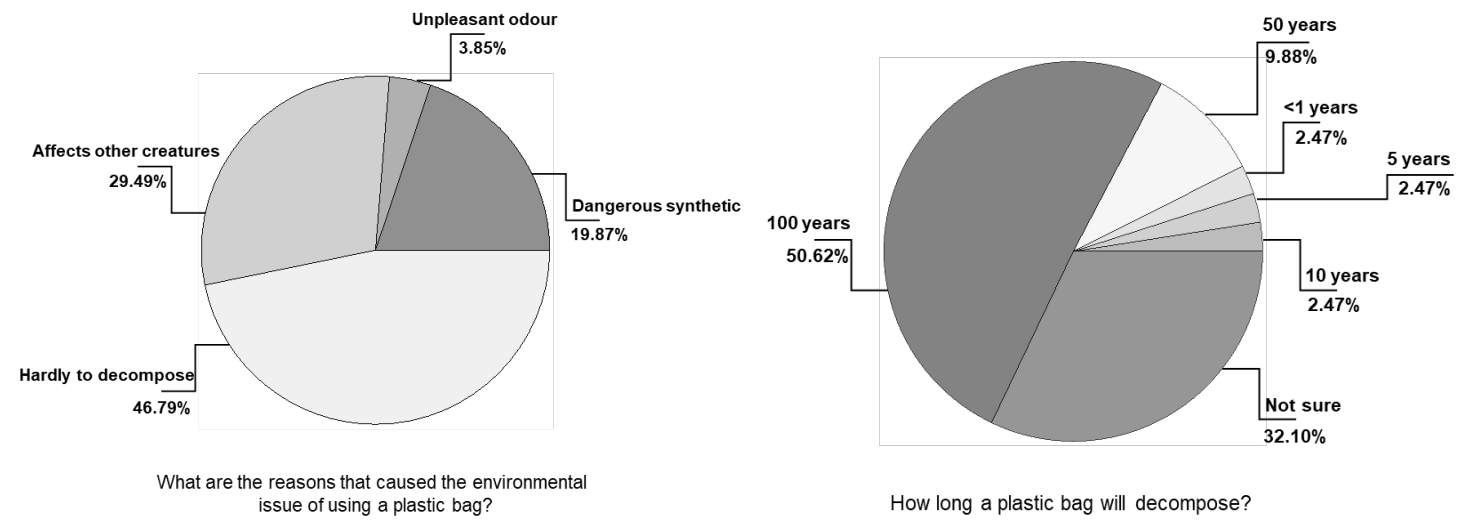

Figure 2: Respondents' awareness and knowledge on the implication of using plastic

Formal and informal education on plastic pollution have increased the students' awareness up to $75.10 \%$. The knowledge was inherited from strong environmental background during secondary school and eventually displayed the support (91.97\%) when entering the university. Additionally, some of the respondents have to enrol for a few environmental courses (e.g. Pollution Ecology and Aquatic Ecology), in the degree and diploma programme. Those courses were offered with the aim to increase the understanding of agricultural activities on environmental cleanliness and factors or materials that can harm the production system. Insufficient awareness from education among the students on plastic pollution has been proven through the uninterested response to care about nature's conservation (Hammami et al., 2017). In this study, the respondents were aware that a PP is difficult to decompose $(46.79 \%)$ and $50.62 \%$ know exactly the time needed for plastic to be totally decomposed. Common ways to dispose PP were to dump it into landfilled or open burning which release multiple toxins pollutant that endangered human health (Okunola et al., 2019). Plastic product also affects other creatures $(29.49 \%)$ especially in marine and also agricultural sectors. Jalil et al. (2013) mentioned that PP hardly decomposed and potentially disturbed the growth of a plant by incapability of roots to pierce them.

\section{Impact of Zero Waste Campus campaign}

After a year of 'no plastic campaign' has been launched (now known as zero-waste campus), $95.18 \%$ respondents are now aware of the campaign and $83.94 \%$ supports the campaign by bringing their own washable food container (Figure 3). The impacts of this campaign are highlighted by the respondents, with $46.01 \%$ who have managed to reduce plastic usage throughout the campus. Other positive outcomes that have been noted by the students are a lesser number of garbage collections per week and that the campus is getting cleaner. However, $<10 \%$ of the respondents gave negative feedback on the campaign where they have to bring their food container with them at all times and or to consume their meals at the food court. Moreover, paying an extra RM0.50 (USD0.12) for each PP that is used for take away is also unpopular among the students. However, $87.15 \%$ of the respondents have expressed that they 
support the campaign only if the food sellers provide discounts whenever the students bring their own food container.

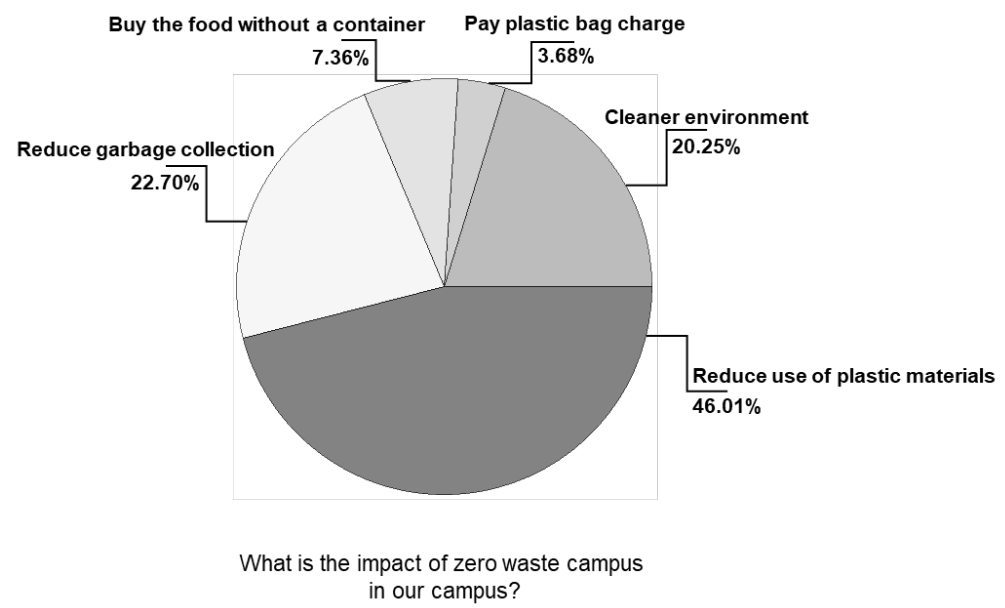

Figure 3: Respondents' perception of zero waste campus in the campus

In order to increase the impact of reducing PP consumption, the implementation of a PP levy was introduced. This has a positive impact on our results where $<10 \%$ of the respondents are ready to pay a levy of MYR0.50 (USD0.12) while the rest prefer to bring their own food containers. This instantly changes the campus environment, which looks better with less waste being generated from food and drinks that are purchased. The effort does not solely depend on the students' responsibility but also needs the complete campus participation such as that of the staffs. A similar impact, on the implementation of plastic levy, has indicated changes in consumer behaviour, and coupled together with education and awareness eventually provide a greater impact (Thomas et al., 2019; Zen et al., 2013). The campus also makes a routine check on the food vendors to ensure that they impose a levy charge on food containers and no longer provide rolled clear plastic, straw, and plastic cups. Even the efforts are seriously taken by the university, the occurrence of the black market giving free PP by a certain vendor has been another issue that needs to be addressed such as introducing a penalty and by issuing a written warning letter to the irresponsible vender. Implementing such penalties literally notifies the food vendors in campus that the university is serious about protecting the campus environment, and in supporting the government's campaign on plastic pollution

\section{Conclusion}

A majority of the respondents are still insistent on using PP in their daily life, although they are significantly aware about plastic pollution. Through a higher acceptance of the zero-waste campaign, regarding plastics usage among the students, a remarkable effect has been seen. Subsequently, only a few students are willing to pay the penalty of MYR0.50 (USD0.21) when they purchase food and drink on campus, mostly when they want to have the meal privately in the residential college or when they have forgotten to bring their food container. The campaign has literally reduced PP usage and garbage collection, and it has also promoted a cleaner environment. It is best if we provide a clearer view of changing the behaviours of using PP through the mass media, by promoting the use of recycling bags, and introducing penalties for those who are negligent in supporting the campaign. Changing starts from creating awareness and is followed by changing behaviours, which later yield the implications of the campaign. 


\section{References}

Afroz, R., Rahman, A., Masud, M. M., \& Akhtar, R. (2017). The knowledge, awareness, attitude and motivational analysis of plastic waste and household perspective in Malaysia. Environmental Science and Pollution Research, 24(3): 2304-2315.

Asmuni, S., Hussin, N. B., Khalili, J. M., \& Zain, Z. M. (2015). Public participation and effectiveness of the no plastic bag day program in Malaysia. Procedia-Social and Behavioral Sciences, 168: 328-340.

Hammami, M. B. A., Mohammed, E. Q., Hashem, A. M., Al-Khafaji, M. A., Alqahtani, F., Alzaabi, S., \& Dash, N. (2017). Survey on awareness and attitudes of secondary school students regarding plastic pollution: Implications for environmental education and public health in Sharjah city, UAE. Environmental Science and Pollution Research, 24(25): 20626-20633.

Heidbreder, L. M., Bablok, I., Drews, S., \& Menzel, C. (2019). Tackling the plastic problem: A review on perceptions, behaviors, and interventions. Science of the Total Environment,(668): 10771093.

Jalil, M. A., Mian, M. N., \& Rahman, M. K. (2013). Using plastic bags and its damaging impact on environment and agriculture: An alternative proposal. International Journal of Learning \& Development, 3(4): 1-14.

Joseph, N., Kumar, A., Majgi, S. M., Kumar, G. S., \& Prahalad, R. B. Y. (2016). Usage of plastic bags and health hazards: A study to assess awareness level and perception about legislation among a small population of Mangalore city. Journal of Clinical and Diagnostic Research, 10(4): 14.

Kale, S. K., Deshmukh, A. G., Dudhare, M. S., \& Patil, V. B. (2015). Microbial degradation of plastic: a review. Journal of Biochemical Technology, 6(2): 952-961.

Kuppusamy, M., \& Gharleghi, B. (2015). "No Plastic Bag Day" concept and its role in Malaysian's environmental behaviour development. Asian Social Science, 11(18): 174-182.

Madigele, P. K., \& Mogomotsi, G. E. J. (2017). "Polluter Pays or Polluter Enriching the Retailers": The case of plastic bag levy failure in Botswana. Ethiopian Journal of Environmental Studies \& Management, 10(4): 472-481.

Moharam, R., \& Maqtari, M. A. A. (2014). The impact of plastic bags on the environment: A field survey of the City of Sana'a and the surrounding Areas, Yemen. International Journal of Engineering Research and Reviews, 2(4): 61-69.

Nurul Zarirah, N., Nusaibah, M., Siti Norbaya, Y., \& Arfah, A. (2016). Consumers buying trend on no plastic bags campaign at shopping mall in Malacca City, Malaysia. International Journal of Business and Management Invention, 5(11): 155-158.

Okunola, A. A., Kehinde, I. O., Oluwaseun, A., \& Olufiropo, E. A. (2019). Public and environmental health effects of plastic wastes disposal: A review. Toxicology and Risk Assessment, 5(2): 113.

Srinivasan, N., Swarnapriya, V., Felix, A. J. W., \& Pravin, T. (2019). Assessment of knowledge and practice on plastics among the professional course students of Annamalai University, Tamil Nadu. International Journal of Community Medicine and Public Health, 6(2): 510-514.

Thomas, G. O., Sautkina, E., Poortinga, W., Wolstenholme, E., \& Whitmarsh, L. (2019). The English plastic bag charge changed behavior and increased support for other charges to reduce plastic waste. Frontiers in Psychology, 10: 1-12.

Xanthos, D., \& Walker, T. R. (2017). International policies to reduce plastic marine pollution from single-use plastics (plastic bags and microbeads): A review. Marine Pollution Bulletin, 118(12): $17-26$.

Zen, I. S., Ahamad, R., \& Omar, W. (2013). No plastic bag campaign day in Malaysia and the policy implication. Environment, Development and Sustainability, 15(5): 1259-1269. 